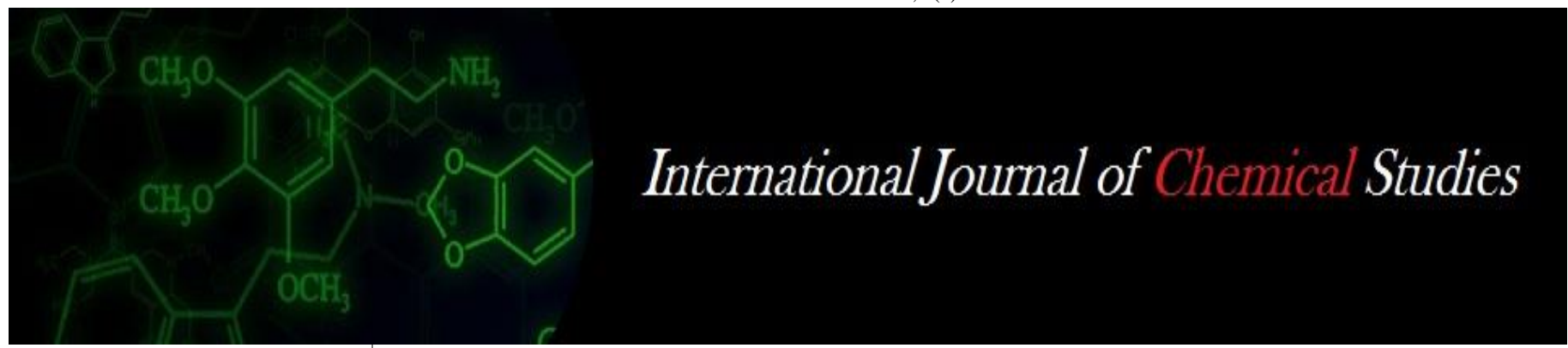

P-ISSN: 2349-8528

E-ISSN: 2321-4902

IJCS 2020; 8(1): 2362-2370

(C) 2020 IJCS

Received: 10-11-2019

Accepted: 12-12-2019

Rajeev Ranjan Thakur Ph.D., Research Scholar, ICAR-CIAE, Nabibagh,

Bhopal, Madhya Pradesh, India

Navin Chandra Shahi

Professor, Department. of

PHP\&FE, GBPUA\&T,

Pantnagar, Uttarakhand, India

Shukadev Mangaraj

Principal Scientist, Dept. of

APPD, ICAR-CIAE,

Nabibagh, Bhopal,

Madhya Pradesh, India

Umesh Chandra Lohani Junior Research Officer, Department of PHP\&FE, GBPUA\&T, Pantnagar,

Uttarakhand, India

\section{Khan Chand}

Junior Research Officer, Department of PHP\&FE, GBPUA\&T, Pantnagar, Uttarakhand, India
Corresponding Author: Rajeev Ranjan Thakur Ph.D., Research Scholar, ICARCIAE, Nabibagh, Bhopal, Madhya Pradesh, India

\section{Effect of apple peel based edible coating material on physicochemical properties of button mushrooms (Agaricus bisporus) under ambient condition}

\author{
Rajeev Ranjan Thakur, Navin Chandra Shahi, Shukadev Mangaraj, \\ Umesh Chandra Lohani and Khan Chand
}

DOI: https://doi.org/10.22271/chemi.2020.v8.i1aj.8622

\begin{abstract}
Button mushroom were coated by dipping in a coating solution for a period of $75 \mathrm{~s}$, formulated by dissolving a combination of apple peel powder and CMC into distilled water. A total of nine different combinations with three levels of apple peel powder concentration $(1.0,1.2$ and $1.4 \% \mathrm{w} / \mathrm{v})$ and three levels of CMC concentration $(1.2,1.5$ and $1.8 \% \mathrm{w} / \mathrm{v})$ were used to prepare the coating solution. To analyse the effect of coating materials on physicochemical properties of button mushroom, the physicochemical responses like weight loss, shrinkage ratio, water activity, color variation, microbial load and free radical scavenging activity were assessed. The higher concentration of apple peel powder was resulting in degradation of colour of coated sample during storage due to anthocyanin content of apple peel powder. The moderate concentration of apple peel powder $(1.2 \% \mathrm{w} / \mathrm{v})$ with high level of CMC concentration $(1.8 \% \mathrm{w} / \mathrm{v})$ were found to be the best combination of coating materials which increased the shelf life of button mushroom upto 5 days along with retaining the quality attributes closest to the fresh sample.
\end{abstract}

Keywords: Apple peel powder, CMC concentration; button mushroom; weight loss; free radical scavenging activity; microbial load

\section{Introduction}

Button mushroom is highly proteinaceous and are used as food and sold as fresh mushroom or is canned and made into soups, sauces and other food products. There are large number of variety of mushrooms are available, but most of them provide almost same amount of same nutrients per serving, regardless of their shape or size (https://www.medicalnewstoday.com/articles/278858.php). Fresh button mushroom contains 90 to 93 per cent moisture. In dried mushroom, 28 to 42.5 percent crude protein, 8.3 to 16.2 per cent crude fibre, 9.4 to 14.5 percent ash, 59.4 percent carbohydrates and 3.1 percent fat, among minerals $71 \mathrm{mg}$ calcium, $912 \mathrm{mg}$ phosphorous, $106 \mathrm{mg}$ sodium, $8.8 \mathrm{mg}$ iron and $2850 \mathrm{mg}$ potassium (per $100 \mathrm{~g}$ dry weight basis) are present. Among the vitamins $8.9 \mathrm{mg}$ thiamine $\left(\mathrm{B}_{1}\right)$, $3.7 \mathrm{mg}$ riboflavin $\left(\mathrm{B}_{2}\right), 26.5 \mathrm{mg}$ ascorbic acid $(\mathrm{C})$ and $42.5 \mathrm{mg}$ niacin $\left(\mathrm{B}_{3}\right)$ are also available on $100 \mathrm{~g}$ dry weight basis. Mushrooms are rich in good quality proteins with lysine and tryptophan that are normally deficient in cereals (Mehta et al., 2011) ${ }^{[8]}$. Mushrooms are rich in proteins and contain all the essential amino acids and of these the rich ones is glutamic acid, aspartic acid and arginine. The lipid fraction of mushrooms contains tocopherol which is an important antioxidant component. Mushrooms are the only non-animal based food that contains vitamin D. Mushrooms also contains large number of volatile compounds which are inbuilt with some enzyme system that are capable of catabolising aromatic substrates, the major one's are 3octone, 3-octanol, 1-octen 3-ol, benzaldehyde, octanol, and 2-octen-1-ol. The presence of dietary fiber (DF) with non-dietary carbohydrates (NDCs) including $\beta$-glucans, polysaccharides-protein complexes (PSPC), chitin, hemicelluloses, mannans, xylans and galactose in mushroom provides several health benefits to the human beings (Rathore et al., 2017) ${ }^{[13]}$. Mushroom consumption gives several medicinal benefits to human health. Such as, High antioxidant content of mushroom helps to get rid of free radicals. 
Free radicals are type of chemical that can harm a person's body cells, potentially leading to cancer. Selenium content of mushroom plays an important role in liver enzyme function, and helps to detoxify some cancer causing compounds in the body. Presence of vitamin D in mushrooms has also been shown to inhibit the growth of cancer cells by contributing to the regulation of the cell growth cycle. Mushrooms are rich in foliate content which helps in DNA synthesis and repair, thus prevents the formation of cancer cells from mutations in the DNA. The fiber, potassium and vitamin $\mathrm{C}$ content in mushrooms all contribute to cardiovascular health. Selenium content of mushroom helps to improve immune response to infection by stimulating the production of killer T-cells. Mushrooms contain two types of dietary fibers in their cell walls, $\beta$-glucans and chitin. These increase satiety and reduce appetite, which makes human body fit, fuller and longer (https://www.medicalnewstoday.com/articles/278858.php).

Mushroom is considered as one of the best tool for diabetes as it contains insulin and enzymes which helps the body to break down the sugar and the starch in the food, keeping the sugar level in the blood under control (http://www.searchhomeremedy.com/5-reasons-howmushrooms-helps-in-controlling-diabetes/).

Although in India the cultivation of mushroom is of recent origin but, with the concentrated efforts of research workers and interested growers, there has been a considerable increase in mushroom production particularly in the last one decade. Mushroom production, which was estimated at 100 tons in 1970 , rose to 400 tons in 1975,1000 tons in 1986, 7000 tons in 1990, 12000 tons in 1992, 25,000 tons in 1993 and more than 50,000 tons at present, out of which $85 \%$ contributing white button mushroom (Karthick and Hamsalakshmi, 2017) [5]. But, in the recent scenario, in a developing nation like India, the major problem for mushroom grower is its shorter shelf life due to the presence of more than 90 percent moisture content and makes it highly perishable after harvest. They develop brown colour on the surface of the cap due to the enzymatic action of phenol oxidase and spoils early (Mehta et al., 2011) ${ }^{[8]}$. Since, mushroom contains highly active, sensitive nutritious and medicinal compound such as tocopherols, flavonoids, carotenoids and ascorbic acid (vitamin- C) therefore, it is a challenging task for the cultivators to prolong the shelf life of button mushroom especially, when continuous market demand is expected along with retaining its quality attributes. There are number of techniques being used for the shelf life extension of button mushroom such as drying, by application of hydrogen peroxide and browning inhibitors (Sapers et al., 2001) ${ }^{[16]}$, by ultrasound treatment, edible coating and many more. Out of all these methods, edible coating is one of easiest and cheapest method by which the shelf life of mushroom can be increased along with conserving its quality characteristics (Nussinovitch and Kampf, 1993) [9]. In the edible coating process, the edible coating formulation is prepared by different organic and inorganic compounds to serve all the essential properties of an edible coating. But, now a day's people are more conscious about the health benefit of use of organic substances in the preservation of button mushroom as it is directly consumed in vegetable. Therefore, in context of enhancing the shelf life of button mushroom, this study was aimed to assess the effect of two organic substance viz. apple peel powder and CMC on physicochemical properties of button mushroom used in its edible coating process.

\section{Materials and methods}

Fresh button mushroom were coated by dipping in a coating solution for $75 \mathrm{~s}$. A total of nine different coating solutions were prepared by dissolving varying apple peel powder concentration $(1.0,1.2$ and $1.4 \% \mathrm{w} / \mathrm{v})$ and $\mathrm{CMC}$ concentration $(1.2,1.5$ and $1.8 \% \mathrm{w} / \mathrm{v})$ into distilled water. To analyse the effect of coating material on physicochemical properties of button mushroom, response parameters were assessed by following formulae for five days during storage.

\section{Weight loss}

The weight loss of coated sample in percentage was calculated by Eq. 1 as given by $\mathrm{Oz}$ and Ulukanli, (2012) ${ }^{[11]}$.

$\mathrm{WL}(\%)=\frac{\mathrm{W}_{\mathrm{i}}-\mathrm{W}_{\mathrm{f}}}{\mathrm{W}_{\mathrm{i}}} \times 100$

Where, $\mathrm{w}_{\mathrm{i}}=$ initial fresh weight of mushroom $(\mathrm{g}), \mathrm{w}_{\mathrm{f}}=$ weight of mushroom on successive day of storage $(\mathrm{g})$.

\section{Shrinkage ratio}

Based on measurement of cap diameter (using digital Vernier Calliper) of button mushroom, shrinkage ratio (SR) was determined by Eq. 2given by giri and Prasd, (2009).

$\mathrm{SR}=\frac{\mathrm{D}_{\mathrm{i}}-\mathrm{D}_{\mathrm{f}}}{\mathrm{D}_{\mathrm{i}}}$

Where, $D_{i}=$ initial cap diameter of fresh mushroom $(\mathrm{mm})$ and $\mathrm{D}_{\mathrm{f}}=$ cap diameter of mushroom on successive day of storage.

\section{Water activity}

A digital water activity meter was used for measuring the water activity of coated button mushroom during each days of storage (Kishore et al., 2011) ${ }^{[6]}$. Samples were kept inside a cavity provided within the instrument and water activity readings were recorded. The temperature during the measurement was kept constant at $25 \pm 1^{\circ} \mathrm{C}$.

\section{Colour measurement}

High resolution images of the mushroom samples were captured using a $13 \mathrm{MP}$ digital camera at $3.6 \mathrm{x}$ zoom. Adobe Photoshop CS 5 software v.12.0 was used to determine L, a, b values. The mean and standard deviation values were determined from the histogram obtained from the software. L, $a, b$ values are not standard colour values and need to be converted to $L^{*}, a^{*}$ and $b^{*}$. The values for $L^{*}, a^{*}, b^{*}$ were evaluated as per the formulae (Eqs. 3-5) given by Yam and Papadakis, (2004) ${ }^{[18]}$.

$$
\begin{aligned}
& \mathrm{L}^{*}=\frac{\mathrm{L}}{255} \times 100 \\
& \mathrm{a}^{*}=\frac{240 \mathrm{a}}{255}-120 \\
& \mathrm{~b}^{*}=\frac{240 \mathrm{~b}}{255}-120
\end{aligned}
$$

The color variation $\left(\Delta \mathrm{E}^{*}\right)$ between the fresh and coated mushroom sample was calculated using the formula prescribed by the International Commission on Illumination (CIE) andgiven by Eq. 8. A $\Delta \mathrm{E}^{*}$ value around 2.3 indicates noticeable difference (Robertson, 1977) ${ }^{[14]}$.

$$
\Delta \mathrm{E}^{*}=\sqrt{\left(\mathrm{L}_{2}^{*}-\mathrm{L}_{1}^{*}\right)^{2}+\left(\mathrm{a}_{2}^{*}-\mathrm{a}_{1}^{*}\right)^{2}+\left(\mathrm{b}_{2}^{*}-\mathrm{b}_{1}^{*}\right)^{2}}
$$


Where, $\Delta \mathrm{E}^{*}=$ Distance matrix (colour variation), $\mathrm{L}_{1}^{*}, \mathrm{~L}_{2}^{*}=$ Luminosity of the coated and fresh samples, respectively. $a_{1}^{*}, a_{2}^{*}=$ green to red values of coated and fresh samples, respectively. $b_{1}^{*}, b_{2}^{*}=$ Yellow to blue values of the coated and fresh samples, respectively.

\section{Microbial load determination}

The total bacterial load was determined every day to observe the antimicrobial effect of coating material on coated mushroom sample during storage. Nutrient agar was used as medium for bacterial growth and plating was done by pour plate method. Serial dilution was done to determine the bacterial growth. Colony forming unit (CFU) pergram of sample was determined by Eq. 7 (Ranganna, 2009) ${ }^{[12]}$ and for analysis purpose its log value were taken.

Colony forming unit $(\mathrm{CFU} / \mathrm{g})=\frac{\text { No.of colonies } \mathrm{X} \text { dilution factor }}{\text { volume of sample taken }}(7)$

\section{Free radical scavenging activity}

The phenolic components of the each sample were extracted by dissolving $10 \mathrm{mg}$ of mushroom in $10 \mathrm{ml}$ of methanol. From each sample, $50 \mu 1$ of the extract was taken in separate test tubes. Then, in each test tubes $950 \mu \mathrm{l}$ of methanol and $3 \mathrm{ml}$ of $0.1 \mathrm{mM}$ methanolic DPPH solution were added. Control was prepared by the same procedure without the sample containing $1 \mathrm{ml}$ of methanol and $3 \mathrm{ml}$ of $0.1 \mathrm{mM}$ methanolic DPPH solution. Methanol was taken as blank. The absorbance for the samples was measured at $517 \mathrm{~nm}$. The percentage free radical scavenging activity (FRSA) was determined by Eq. 8 (Tajalli et al., 2015) ${ }^{[17]}$.

$\%$ FRSA $=\frac{\text { Absorbance of control-Absorbance of sample }}{\text { Absorbance of control }} \times 100(8)$

\section{Statistical analysis}

The test of significance of coating material on physicochemical properties of button mushroom was done in by two way ANOVA for initial five days of storage and it was carried out in Microsoft Excel 2016.

\section{Results and Discussion}

The effect of different levels of coating materials (apple peel powder concentration and CMC concentration) along with storage days on quality parameters of coated button mushroom has been checked by two way ANOVA. The analysis for assessing the effect of coating materials on edible coated button mushroom was carried out for initial 5 days, as at the end of $5^{\text {th }}$ day, all samples were spoiled due to excess microbial growth.

\section{Effect of apple peel powder and CMC concentration on weight loss and shrinkage ratio (diameter) of coated button mushroom during storage}

Variation in weight loss of coated button mushroom during storage at different levels of apple peel powder concentration with constant CMC concentration $(1.8 \% \mathrm{w} / \mathrm{v})$ and dipping time $(75 \mathrm{~s})$ is represented in Fig. 1. It is clear from the figure that all the three different lines coincided to each other, which shows that the effect of different levels of apple peel powder concentration on weight loss of coated sample was insignificant $(p>0.05)$. However, the weight loss of coated samples were significantly $(p<0.05)$ increased from 4 to $26 \%$ during storage days Table 1 . It may be due to high perishable nature of button mushroom (Jiang, 2013) ${ }^{[3]}$. Furthermore, similar effects of different levels of apple peel powder concentration $(\% \mathrm{w} / \mathrm{v})$ and storage days were also observed on shrinkage ratio (diameter) of coated button mushroom during storage.

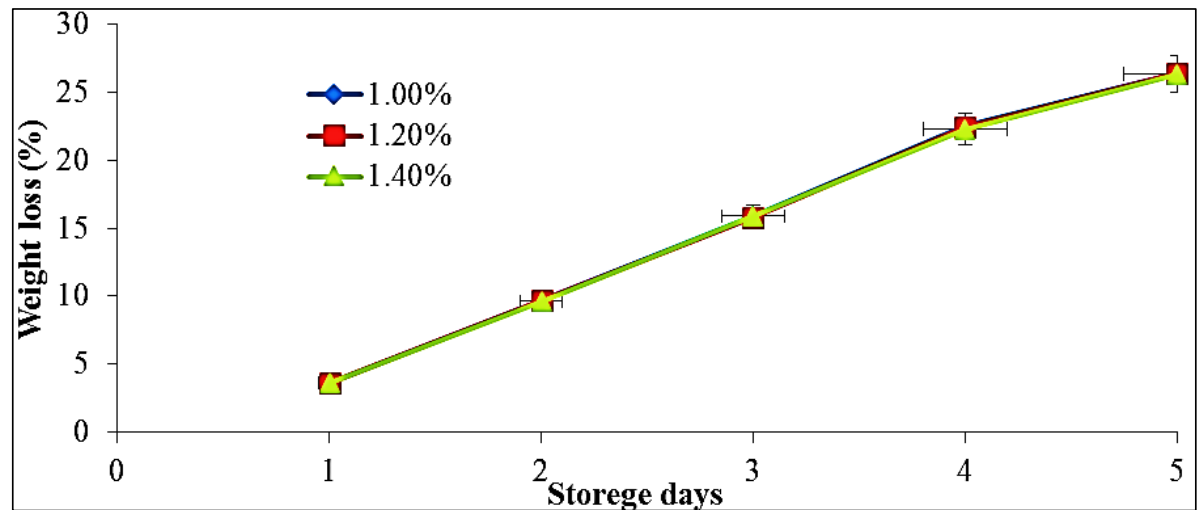

Fig 1: Effect of different levels of apple peel powder concentration on weight loss of coated button mushroom (values \pm SD)

Table 1: ANOVA for weight loss at different levels of apple peel powder concentration on coated mushroom samples during storage

\begin{tabular}{|c|c|c|c|c|}
\hline Source of Variation & Df & Sum of Squares & Mean Squares & p-value \\
\hline Levels of APP Conc. & 2 & 0.019 & 0.0094 & 0.19 \\
\hline Storage days & 4 & 1019.5 & 254.9 & $<0.05$ \\
\hline Error & 8 & 0.037 & 0.004 & \\
\hline Total & 14 & 1019.56 & & \\
\hline
\end{tabular}

Moreover, the variation in weight loss of coated button mushroom during storage at different levels of $\mathrm{CMC}$ concentration with constant apple peel powder concentration $(1.2 \% \mathrm{w} / \mathrm{v})$ and dipping time $(75 \mathrm{~s})$ is presented in Fig. 2 . It is clear from the figure that all the three different lines were not coincided to each other, which shows that the effect of different levels of CMC concentration on weight loss of coated sample was significant $(p<0.05)$. It was also observed from the Fig. 2 that, at lower level of CMC concentration $(1.2 \% \mathrm{w} / \mathrm{v})$ the weight loss was higher as compared to that at higher level of CMC concentration $(1.8 \% \mathrm{w} / \mathrm{v})$. It could be attributed to the fact that at high level of $\mathrm{CMC}$ concentration, the binding property of coating formulation on mushroom surface was increased, which were retarded the rate of loss of moisture from the product to the environment and reduced the weight loss. However, the weight loss of coated samples were significantly $(p<0.05)$ increased from 4 to $26 \%$ during storage days (Table 2). Similar effect of different levels alginate concentration on weight loss in the alginate coating of button mushroom was reported by Jiang, (2013) ${ }^{[3]}$. 


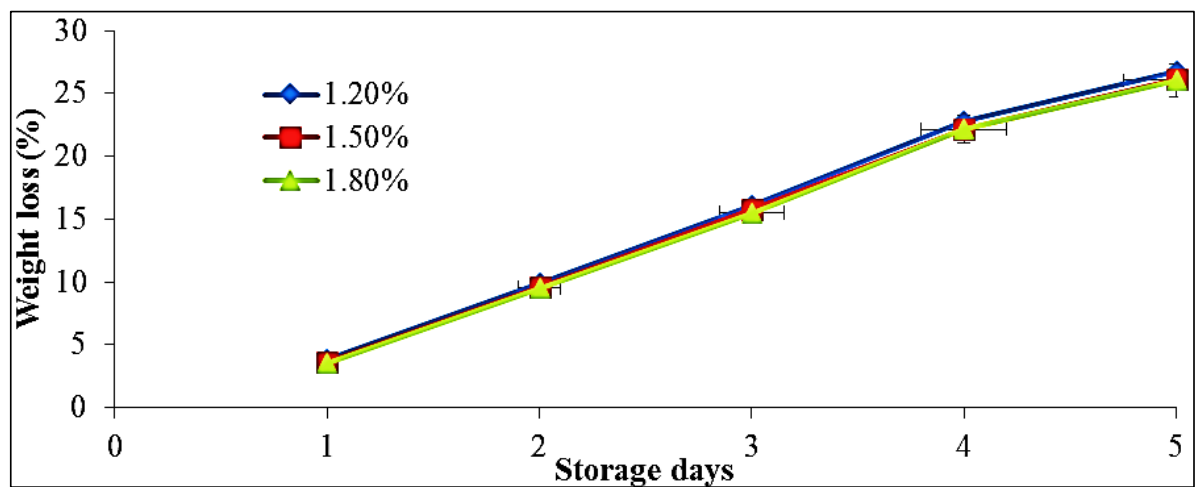

Fig 2: Effect of different levels of CMC concentration on weight loss of coated button mushroom (values \pm SD)

Table 2: ANOVA for weight loss at different levels of CMC concentration on coated mushroom samples during storage

\begin{tabular}{|c|c|c|c|c|}
\hline Source of Variation & Df & Sum of Squares & Mean Squares & p-value \\
\hline Levels of CMC Conc. & 2 & 0.746 & 0.373 & $<0.05$ \\
\hline Storage days & 4 & 1013.9 & 253.48 & $<0.05$ \\
\hline Error & 8 & 0.086 & 0.01 & \\
\hline Total & 14 & 1014.74 & & \\
\hline
\end{tabular}

Additionally, the change in shrinkage ratio (diameter) of coated button mushroom during storage at different levels of CMC concentration with constant apple peel powder concentration $(1.2 \% \mathrm{w} / \mathrm{v})$ and dipping time $(75 \mathrm{~s})$ is depicted in Fig. 3. From the figure, it was observed that all the three lines of different levels of CMC concentration was not coincided to each other, which shows that the effect of different levels of CMC concentration on shrinkage ratio (diameter) of coated sample was significant $(p<0.05)$ (Table $3)$. It was also observed from the Fig. 3 that, at lower level of CMC concentration $(1.2 \% \mathrm{w} / \mathrm{v})$ the shrinkage ratio was higher as compared to that at higher level of CMC concentration $(1.8 \% \mathrm{w} / \mathrm{v})$. It was also due to the fact that, at higher level of CMC concentration in coating formulation, the rate of retardation in moisture loss from the product was greater as compared to that of lower level of CMC concentration in coating formulation. However, the shrinkage ratio (diameter) was significantly $(p<0.05)$ increased from 0.01 to 0.13 during storage days (Table 3 ).

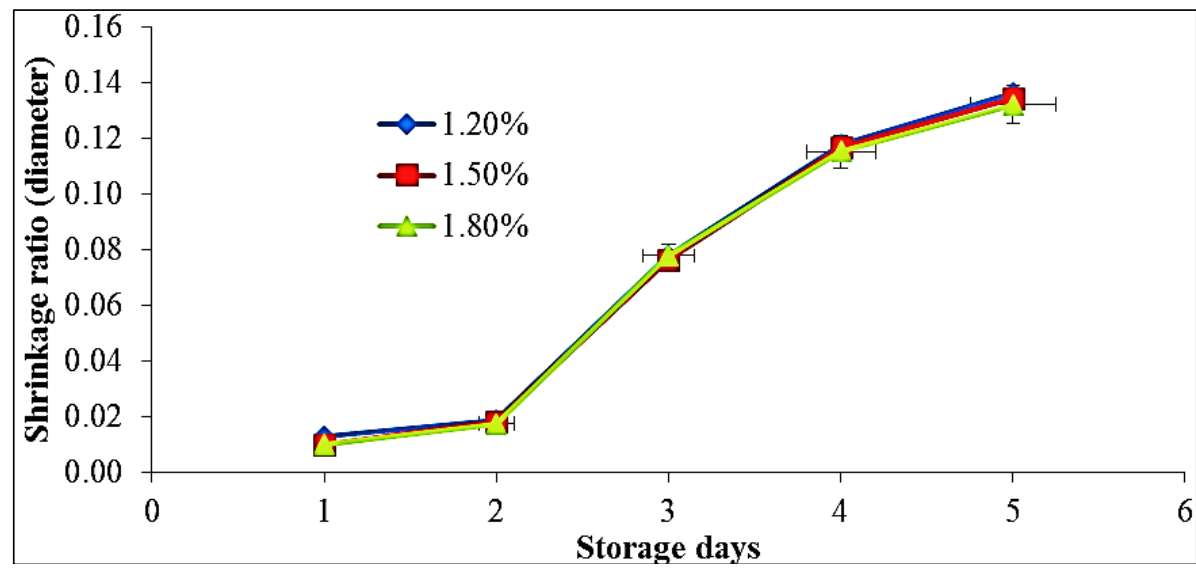

Fig 3: Effect of different levels of CMC concentration on shrinkage ratio (diameter) of coated button mushroom (values \pm SD)

Table 3: ANOVA for shrinkage ratio at different levels of CMC concentration on coated mushroom samples during storage

\begin{tabular}{|c|c|c|c|c|}
\hline Source of Variation & Df & Sum of Squares & Mean Squares & p-value \\
\hline Levels of CMC Conc. & 2 & $5.14 E-5$ & $2.57 E-5$ & $<0.05$ \\
\hline Storage days & 4 & 0.02 & 0.005 & $<0.05$ \\
\hline Error & 8 & $1.52 E-5$ & $1.9 E-6$ & \\
\hline Total & 14 & 0.021 & & \\
\hline
\end{tabular}

Effect of apple peel powder concentration and CMC concentration on water activity of coated button mushroom during storage

The effect of different levels of apple peel powder concentration at constant CMC concentration $(1.8 \% \mathrm{w} / \mathrm{v})$ and dipping time (75s) on water activity of coated button mushroom was found non-significant $(p>0.05)$. However, water activity of coated samples was significantly $(p<0.05)$ decreased from 0.98 to 0.93 during storage days (Table 4). Moreover, the effect of different levels of CMC concentration at constant apple peel powder concentration $(1.2 \% \mathrm{w} / \mathrm{v})$ and dipping time (75s) on water activity of coated button mushroom is shown in Fig. 4. From the figure, it was obvious that all the three lines were not coincided to each other, which revealed that the effect of different levels of CMC concentration on water activity of coated button mushroom was significant $(p<0.05)$ (Table 5). It was well clear from the Fig. 4 that, at lower level of CMC concentration the decrease in water activity of coated sample was more as compare to higher level of CMC concentration. It could be attributed to the fact that, higher levels of CMC concentration strengthen the barrier property of coating formulation which ultimately decreased the loss of water from the product during storage. The similar effect of different levels of CMC concentration on water activity of coated fruits and vegetable was also reported by Kishore et al., (2011) ${ }^{[6]}$ and concluded that the higher level of CMC concentration strengthen the barrier property of coating solution. 
Table 4: ANOVA for water activity at different levels of apple peel powder concentration on coated mushroom samples during storage

\begin{tabular}{|c|c|c|c|c|}
\hline Source of Variation & Df & Sum of Squares & Mean Squares & p-value \\
\hline Levels of APP Conc. & 2 & 0.028 & 0.014 & 0.21 \\
\hline Storage days & 5 & 1243.67 & 248.73 & $<0.05$ \\
\hline Error & 10 & 0.087 & 0.009 & \\
\hline Total & 17 & 1243.81 & & \\
\hline
\end{tabular}

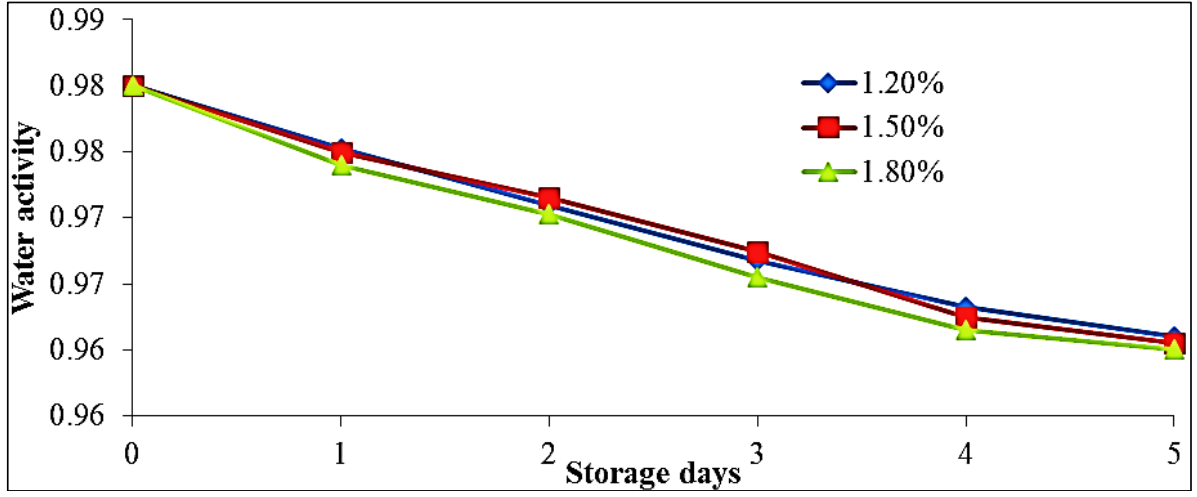

Fig 4: Effect of different levels of CMC concentration on water activity of coated button mushroom (values \pm SD)

Table 5: ANOVA for water activity at different levels of CMC concentration on coated mushroom samples during storage

\begin{tabular}{|c|c|c|c|c|}
\hline Source of Variation & Df & Sum of Squares & Mean Squares & p-value \\
\hline Levels of CMC Conc. & 2 & $3.84 E-6$ & $1.92 E-6$ & $<0.05$ \\
\hline Storage days & 5 & $8.37 E-4$ & $1.67 E-4$ & $<0.05$ \\
\hline Error & 10 & $1.91 E-6$ & $1.91 E-7$ & \\
\hline Total & 17 & $8.43 E-4$ & & \\
\hline
\end{tabular}

Effect of apple peel powder and CMC concentration on color variation $\left(\Delta E^{*}\right)$ of coated button mushroom during storage

Variation in color $\left(\Delta \mathrm{E}^{*}\right)$ of coated button mushroom during storage at different levels of apple peel powder concentration with constant CMC concentration $(1.8 \% \mathrm{w} / \mathrm{v})$ and dipping time (75s) is represented in Fig. 5. It is clear from the figure that there was a fair bit of gap between the three different lines, which shows that the effect of different levels of apple peel powder concentration on color variation of coated sample was significant $(p<0.01)$ (Table 6). It can be also clearly seen from the figure that at higher level of apple peel powder concentration, the variation in color $\left(\Delta \mathrm{E}^{*}\right)$ of the coated sample was more than that at lower level. This effect was parallel to the result of color variation of alginate coated button mushroom found by Jiang, (2013) [3]. It could be attributed to the fact that, with increase in the level of apple peel powder concentration, the amount of anthocyanin content in coating solution was increased and thus, the darkness of coating formulation was increased which were resulted in high color variation of the coated samples (Sangolagi et al., 2015) ${ }^{[15]}$. Further, the color variation of the coated samples from the fresh sample at different level of apple peel powder concentration during storage days were significantly $(p<0.05)$ increased from 1.7 to 6.5 . It might be due to enzymic browning of mushroom itself and browning of apple peel powder during storage (Table 6).

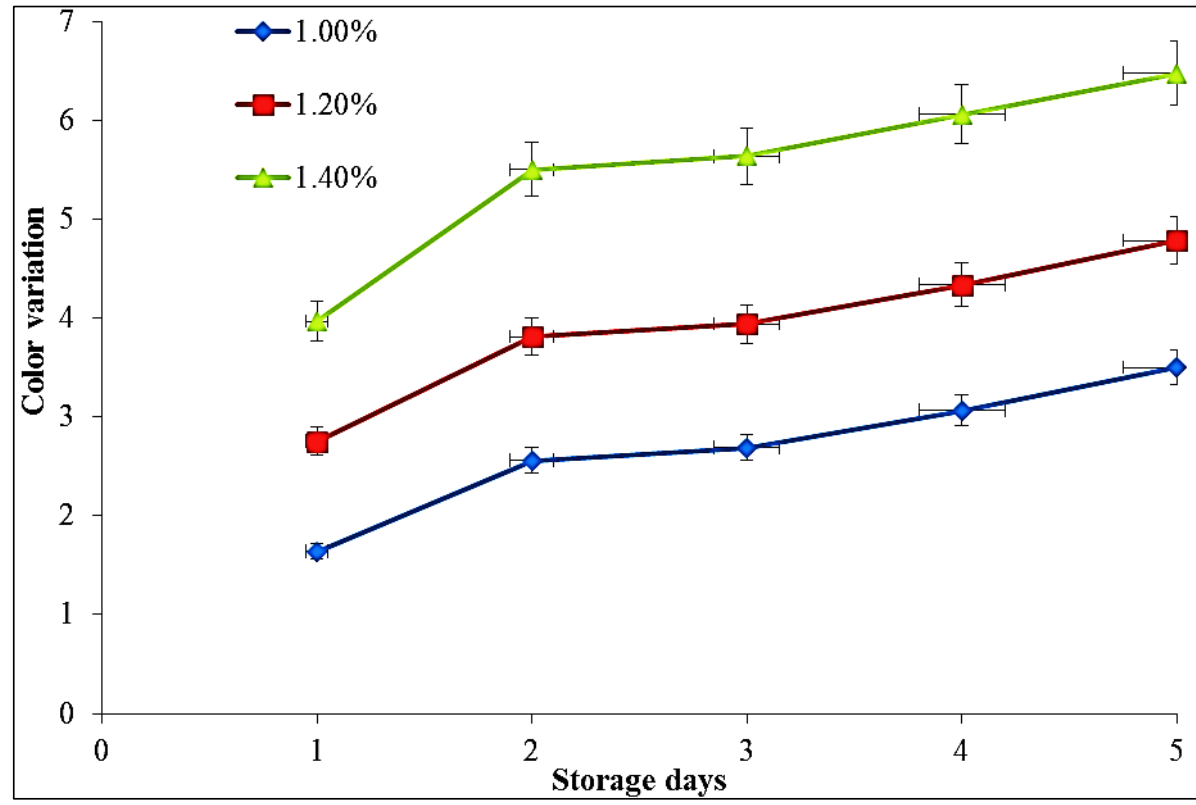

Fig 5: Effect of different levels of apple peel powder concentration on colour $\left(\Delta \mathrm{E}^{*}\right)$ of coated button mushroom (values \pm SD) 
Table 6: ANOVA for color variation at different levels of apple peel powder concentration on coated mushroom samples during storage

\begin{tabular}{|c|c|c|c|c|}
\hline Source of Variation & Df & Sum of Squares & Mean Squares & p-value \\
\hline Levels of APP Conc. & 2 & 20.22 & 10.11 & $<0.01$ \\
\hline Storage days & 4 & 7.66 & 1.91 & $<0.05$ \\
\hline Error & 8 & 0.18 & 0.022 & \\
\hline Total & 14 & 28.05 & & \\
\hline
\end{tabular}

APP-apple peel powder, Conc.-Concentration

Moreover, the variation in color $\left(\Delta \mathrm{E}^{*}\right)$ of coated button mushroom during storage at different levels of $\mathrm{CMC}$ concentration with constant apple peel powder concentration
$(1.2 \% \mathrm{w} / \mathrm{v})$ and dipping time $(75 \mathrm{~s})$ is represented in Fig. 6. It was observed from the figure that the effect of different levels of CMC concentration on color variation of coated samples were significant $(p<0.01)$ (Table 7$)$. It was also very clear from the Fig. 6 that, at higher level of CMC concentration the color variation of coated sample from fresh sample was more than that at lower level. It could be due to the fact that, as the $\mathrm{CMC}$ concentration was increased the adhesiveness of coating formulation on the product surface was also increased and due to this more amount of coating solution was adhered on product surface and thus finally, the color variation was increased (Nussinovitch and Kampf, 1993) ${ }^{[9]}$.

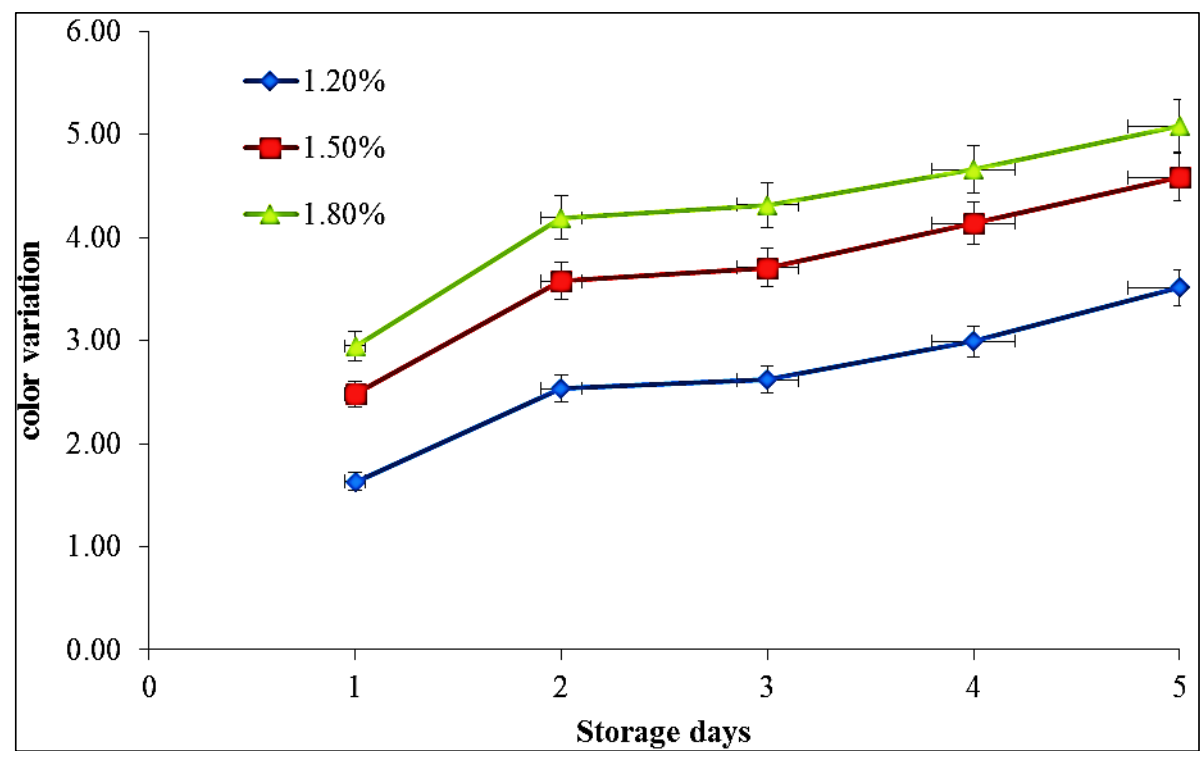

Fig 6: Effect of different levels of CMC concentration on colour $\left(\Delta \mathrm{E}^{*}\right)$ of coated button mushroom (values $\pm \mathrm{SD}$ )

Table 7: ANOVA for color variation at different levels of CMC concentration on coated mushroom samples during storage

\begin{tabular}{|c|c|c|c|c|}
\hline Source of Variation & Df & Sum of Squares & Mean Squares & p-value \\
\hline Levels of CMC Conc. & 2 & 6.46 & 3.23 & $<0.01$ \\
\hline Storage days & 4 & 6.89 & 1.72 & $<0.05$ \\
\hline Error & 8 & 0.056 & $7.1 E-3$ & \\
\hline Total & 14 & 13.41 & & \\
\hline
\end{tabular}

CMC-carboxymethyl cellulose, Conc. - Concentration

Effect of apple peel powder and CMC concentration on microbial load of coated button mushroom during storage Variation in microbial load of coated button mushroom during storage at different levels of apple peel powder concentration with constant CMC concentration $(1.8 \% \mathrm{w} / \mathrm{v})$ and dipping time (75s) is shown in Fig. 7. It is clear from the Table 8 that the effect of different levels of apple peel powder concentration on microbial load of coated sample was significant $(p<0.05)$. It was also observed from Fig. 7 that at higher level of apple peel powder concentration the microbial load of coated button mushroom samples were low as compare to that at lower level. It could be attributed to the fact that, at higher level of apple peel powder concentration, the antimicrobial effect of coating solution was increased. When the fresh samples were dipped into the coating solution, the antimicrobial effect of coating solution was imparted to the product and thus, lowered down the magnification of microbial load (Chebaibi and Filali, 2013) ${ }^{[1]}$. However, the microbial load of coated samples were significantly $(p<0.01)$ increased from 5.6 to $14.9 \mathrm{log}(\mathrm{CFU} / \mathrm{g})$ during storage days and this may be attributed to the fact that mushroom is a crop which belongs to funzilla group and are highly susceptible to microbial attack after harvesting (Table 8). Furthermore, the variation in microbial load of coated button mushroom during storage at different levels of CMC concentration with constant apple peel powder concentration $(1.2 \% \mathrm{w} / \mathrm{v})$ and dipping time (75s) is represented in Fig. 8. It was observed from Table 9 that the effect of different levels of CMC concentration, the variation in microbial load of coated samples were significant $(p<0.05)$. It was also very clear from the Fig. 8 that at higher levels of CMC concentration the microbial load of coated samples were low as compare to lower level of CMC concentration. This could be due to the fact that at higher level of CMC concentration in coating solution, the barrier property of coating formulation was increased and were restricted the microbial attack on coated button mushroom samples from outside. This effect of CMC concentration on microbial load of button mushroom was very much similar to the effect of chitosan-glucose complex coating on shitake mushroom as reported by Jiang et al. (2012) ${ }^{[4]}$. 


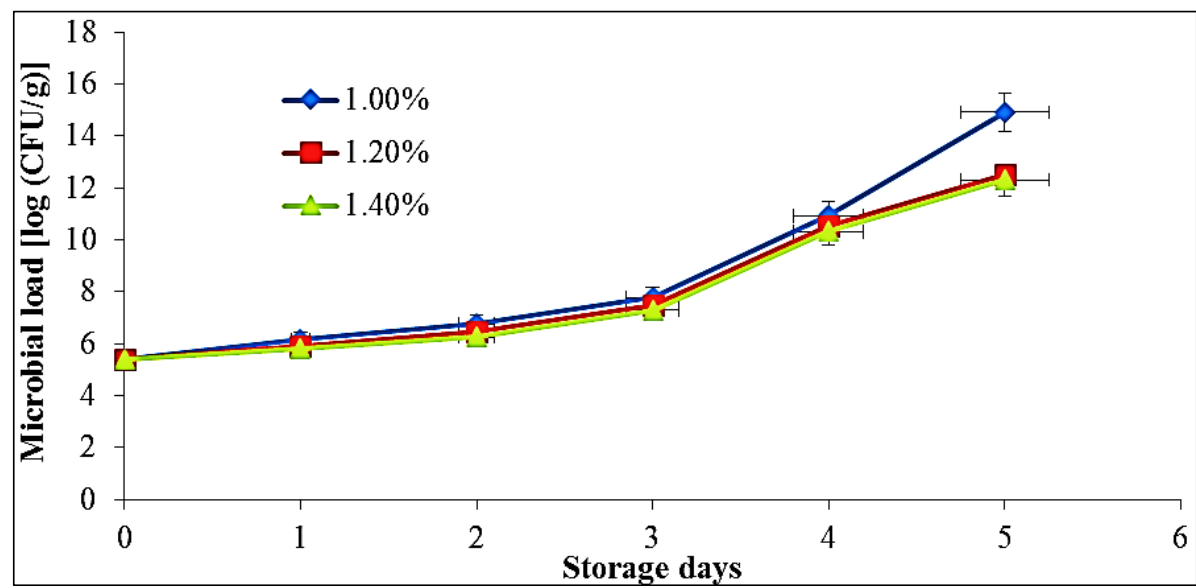

Fig 7: Effect of different levels of apple peel powder concentration on microbial load of coated button mushroom (values \pm SD)

Table 8: ANOVA for microbial load at different levels of apple peel powder concentration on coated mushroom samples during storage

\begin{tabular}{|c|c|c|c|c|}
\hline Source of Variation & Df & Sum of Squares & Mean Squares & p-value \\
\hline Levels of APP Conc. & 2 & 1.97 & 0.98 & $<0.01$ \\
\hline Storage days & 5 & 142.61 & 28.52 & $<0.01$ \\
\hline Error & 10 & 2.78 & 0.28 & \\
\hline Total & 17 & 147.29 & & \\
\hline
\end{tabular}

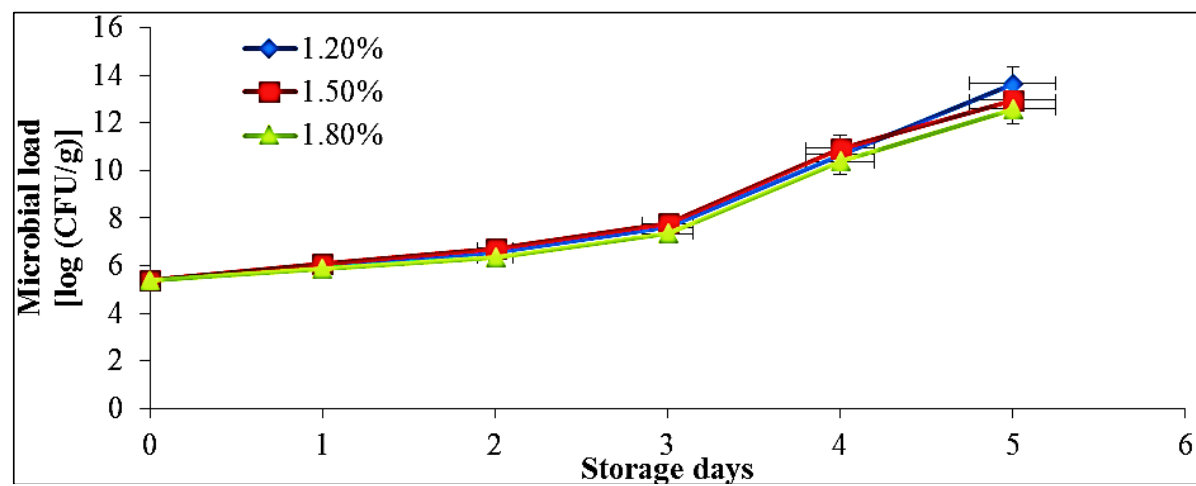

Fig 8: Effect of different levels of CMC concentration on microbial load of coated button mushroom (values \pm SD)

Table 9: ANOVA for microbial load at different levels of CMC concentration on coated mushroom samples during storage

\begin{tabular}{|c|c|c|c|c|}
\hline Source of Variation & Df & Sum of Squares & Mean Squares & p-value \\
\hline Levels of CMC Conc. & 2 & 0.40 & 0.20 & $<0.05$ \\
\hline Storage days & 5 & 137.18 & 27.44 & $<0.01$ \\
\hline Error & 10 & 0.52 & 0.052 & \\
\hline Total & 17 & 138.10 & & \\
\hline
\end{tabular}

Effect of apple peel powder concentration and CMC concentration on \% FRSA of coated button mushroom during storage

Variation in free radical scavenging activity of coated button mushroom during storage at different levels of apple peel powder concentration with constant CMC concentration $(1.8 \% \mathrm{w} / \mathrm{v})$ and dipping time $(75 \mathrm{~s})$ is shown in Fig. 9. From the figure, it was clearly observed from the figure that the change in free radical scavenging activity of coated button mushroom at different levels of apple peel powder concentration was insignificant $(p>0.05)$. It could be related to the fact that at constant CMC concentration $(1.5 \% \mathrm{w} / \mathrm{v})$ and dipping time $(60 \mathrm{~s})$, with increasing the level of apple peel powder concentration from 1.0 to $1.4 \% \mathrm{w} / \mathrm{v}$, the absorbance of antioxidant compounds from the coating solution by the samples was reaches upto its saturation level. However, the decrease in free radical scavenging activity (FRSA) was found only $14.8 \%$ during $4^{\text {th }}$ day of storage and was also insignificant $(p>0.05)$ (Table 10). It could be related to the fact that the barrier developed by coating formulation around the mushroom surface in the coating process was assisted to minimize the loss of antioxidant compounds from the coated samples during storage (Li et al., 2006) ${ }^{[7]}$. 


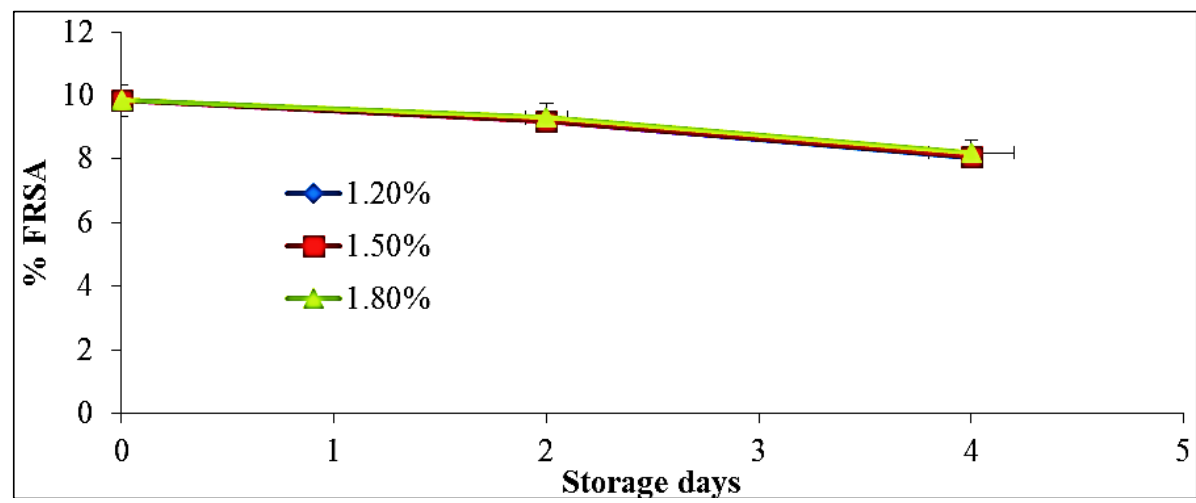

Fig 9: Effect of different levels of apple peel powder concentration on \% FRSA of coated button mushroom (values \pm SD)

Table 10: ANOVA for free radical scavenging activity at different levels of apple peel powder concentration on coated mushroom samples during storage

\begin{tabular}{|c|c|c|c|c|}
\hline Source of Variation & Df & Sum of Squares & Mean Squares & p-value \\
\hline Levels of APP Conc. & 2 & 0.003 & $1.57 E-3$ & 0.14 \\
\hline Storage days & 2 & 0.082 & 0.041 & 0.16 \\
\hline Error & 4 & 0.002 & $4.79 E-4$ & \\
\hline Total & 8 & 4.73 & & \\
\hline
\end{tabular}

Moreover, the variation in free radical scavenging activity of coated button mushroom during storage at different levels of CMC concentration with constant apple peel powder concentration $(1.2 \% \mathrm{w} / \mathrm{v})$ and dipping time $(75 \mathrm{~s})$ is depicted in Fig. 10. It was observed from the figure that, the change in free radical scavenging activity of coated button mushroom at different levels of CMC concentration was insignificant $(p>0.05)$. It may be due to the fact that at constant apple peel powder concentration $(1.2 \% \mathrm{w} / \mathrm{v})$ and dipping time $(60 \mathrm{~s})$, with increasing the level of CMC concentration from 1.2 to $1.8 \% \mathrm{w} / \mathrm{v}$, the absorbance of antioxidant compounds from the coating solution by button mushroom was not changed much more. Further, the decrease in free radical scavenging activity of coated button mushroom was also insignificant $(p>0.05)$ (Table 11) during storage and was decreased only by $15.1 \%$ on $4^{\text {th }}$ day of storage. It could be attributed to the fact that the coating formulation not only imparted the antioxidant characteristics to the samples, it also minimized the loss of antioxidant compounds from the coated samples during storage by providing a protective barrier for active ingredients present in the product (Oms-Olieu et al., 2008) ${ }^{[10]}$.

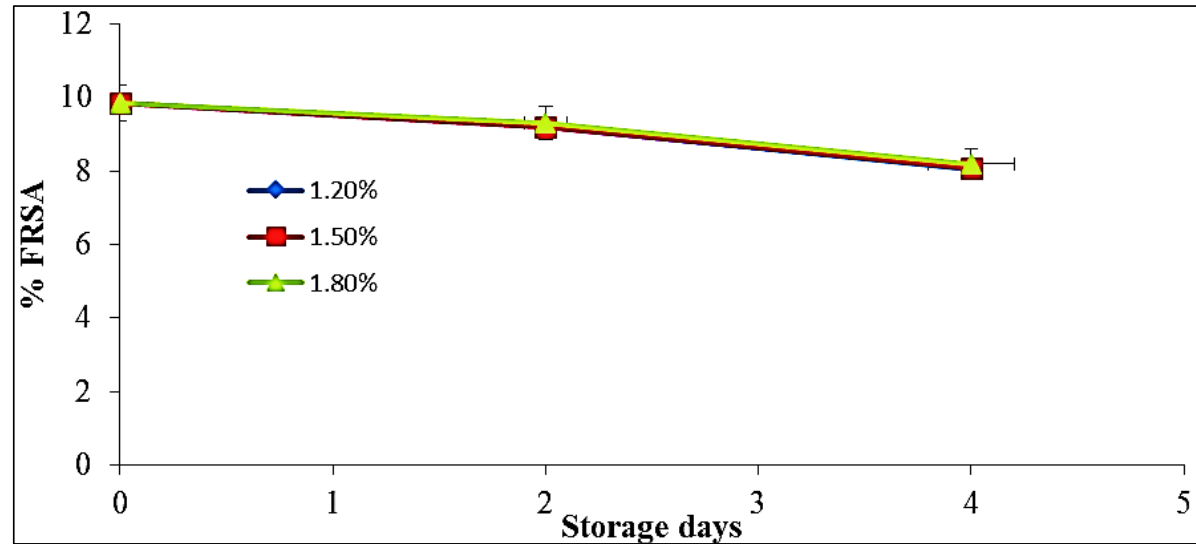

Fig 10: Effect of different levels of CMC concentration on \% FRSA of coated button mushroom (values \pm SD)

Table 11: ANOVA for free radical scavenging activity at different levels of CMC concentration on coated mushroom samples during storage

\begin{tabular}{|c|c|c|c|c|}
\hline Source of Variation & Df & Sum of Squares & Mean Squares & p-value \\
\hline Levels of CMC Conc. & 2 & 0.011 & 0.006 & 0.12 \\
\hline Storage days & 2 & 0.69 & 0.35 & 0.17 \\
\hline Error & 4 & 0.006 & $1.54 E-3$ & \\
\hline Total & 8 & 4.69 & & \\
\hline
\end{tabular}

\section{Conclusion}

The different constituent of coating formulation serves different purposes for coated product. Such as, binding agent (i.e. CMC) and antioxidant agent (apple peel powder) of coating solution provides protective barrier to microbial attack from outside and helps in minimizing the loss of active ingredients from the coated product during storage, respectively. Therefore, it was essential to use the combination of apple peel powder and CMC for coating of button mushroom to increase its shelf life. It was found that the higher concentration of apple peel powder degraded the colour of coated sample. Hence, it was concluded that the apple peel powder concentration of $1.2 \% \mathrm{w} / \mathrm{v}$ with high level of CMC concentration $1.8 \% \mathrm{w} / \mathrm{v}$ was the best combination out of all combination taken and at which, the shelf life of button mushroom was found to be 5 days.

\section{Acknowledgements}

This study was supported by technical quality improvement programme (TQIP-II) in Govind Ballabh Pant University of Agriculture and Technology (GBPUA\&T).

\section{References}

1. Chebaibi A, Filali FR. Bactericidal activity and phytochemical screening of apple peel aqueous extracts. Journal of Medicinal Plants Research. 2013; 7(14):887891. 
2. Giri SK, Prasad S. Quality and moisture sorption characteristics of microwave-vacuum, air and freeze-dried button mushroom (Agaricus bisporus). Journal of Food Processing and Preservation. 2009; 33:237-251.

3. Jiang T. Effect of alginate coating on physicochemical and sensory qualities of button mushrooms (Agaricus bisporus) under a high oxygen modified atmosphere. Postharvest biology and technology. 2013; 76:91-97.

4. Jiang $\mathrm{T}$, Feng L, Li J. Changes in microbial and postharvest quality of shiitake mushroom (Lentinus edodes) treated with chitosan-glucose complex coating under cold storage. Food Chemistry. 2012; 131(3):780786.

5. Karthick K, Hamsalakshmi H. Current scenario of mushroom industry in India. International Journal of Commerce and Management Research. 2017; 3(3):23-26.

6. Kishore K, Pathak KA, Shukla R, Bharali R. Effect of storage temperature on physico-chemical and sensory attributes of purple passion fruit (Passiflora edulis Sims). Journal of food science and technology. 2011; 48(4):484488.

7. Li Y, Guo C, Yang J, Wei J, Xu J, Cheng S. Evaluation of antioxidant properties of pomegranate peel extract in comparison with pomegranate pulp extract. Food chemistry. 2006; 96(2):254-260.

8. Mehta BK, Jain SK, Sharma GP, Doshi A, Jain HK. Cultivation of button mushroom and its processing: a techno-economic feasibility. International Journal of Advanced Biotechnology and Research. 2011; 2(1):201207.

9. Nussinovitch A, Kampf N. Shelf-life extension and conserved texture of alginate-coated mushrooms (Agaricus bisporus). LWT-Food Science and Technology. 1993; 26(5):469-475.

10. Oms-Oliu G, Soliva-Fortuny R, Martín-Belloso O. Using polysaccharide-based edible coatings to enhance quality and antioxidant properties of fresh-cut melon. LWT-Food science and technology. 2008; 41(10):1862-1870.

11. Oz AT, Ulukanli Z. Application of edible starch-based coating including glycerol plus oleum nigella on arils from long-stored whole pomegranate fruits. Journal of Food Processing and Preservation. 2012; 36(1):81-95.

12. Rangnna $\mathrm{S}$. Handbook of analysis and quality control for fruit and vegetables. Tata McGraw Hill Publication Company limited, New Delhi. 375-376, 2009.

13. Rathore H, Prasad S, Sharma S. Mushroom nutraceuticals for improved nutrition and better human health: A review. Pharma Nutrition. 2017; 5(2):35-46.

14. Robertson AR. The CIE 1976 color-difference formulae. Color Research \& Application. 1977; 2(1):711.

15. Sangolagi D, Bhosale MG, Gaikwad N. Effect of different pre-treatments on minimally processed pomegranate arils during storage. International journal of Science, Engineering and Technology. 2015; 3(4):11121116.

16. Sapers GM, Miller RL, Pilizota V, Kamp F. Shelf-life extension of fresh mushrooms (Agaricus bisporus) by application of hydrogen peroxide and browning inhibitors. Journal of Food Science. 2001; 66(2):362-366.

17. Tajalli F, Malekzadeh K, Soltanian H, Janpoor J, Rezaeian S, Pourianfar HR. Antioxidant capacity of several Iranian, wild and cultivated strains of the button mushroom. Brazilian Journal of Microbiology. 2015; 46(3):769-776.

18. Yam KL, Papadakis SE. A simple digital imaging method for measuring and analyzing color of food surfaces. Journal of food engineering. 2004; 61(1):137142.

19. https://www.medicalnewstoday.com/articles/278858.php. Benefits of mushroom consumption to human health. Accessed on, 2020.

20. http://www.searchhomeremedy.com/5-reasons-howmushrooms-helps-in-controlling-diabetes/. Medicinal benefits of mushroom consumption. Accessed on, 2020. 